\title{
Forming Student Online Teams For Maximum Performance
}

\author{
Joel D. Olson, Kaplan University, USA
}

Darlene G. Ringhand, DeVry University, USA

Ray C. Kalinski, Kaplan University, USA

James G. Ziegler, Kaplan University, USA

\begin{abstract}
What is the best way to assign graduate business students to online team-based projects? Team assignments are frequently made on the basis of alphabet, time zones or previous performance. This study reviews personality as an indicator of student online team performance. The personality assessment IDE (Insights Discovery Evaluator) was administered to 450 students in the first six-week course of a proprietary online university MBA program. The IDE was utilized for the study because the university had selected the IDE as a part of its business curriculum. In the second week, students were randomly placed on 138 virtual teams and quantitative data collected from an assignment where students self-reported their IDE type. A qualitative method was used to determine subject IDE type in those cases where subjects did not clearly identify their type. Performance was measured using three instructor-graded assignments completed during the course. Student virtual teams were categorized as random, variable and dominant, contingent upon the composition of team personality types. This study found no statistically significant relationship between IDE's personality types or the cognitive trait variables of attitude (extroversion and introversion) or trait function (thinking and feeling) on team performance. Personality trait did not appear to be a variable with the intentional formation of higher performing online student teams. All personality traits performed equally as well. Personality Bias (IDE type homogeneity) was the closest to being statistically significant as a factor in virtual team performance. A model is presented suggesting the relationship between personality and performance.
\end{abstract}

Keywords: Virtual Teams; Online Teams; Team Performance; Online Learning; Distance Education; Virtual Management; Insights Discovery Evaluator; Team Personality and Performance; Personality Bias and Team Performance

\section{INTRODUCTION}

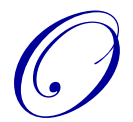

nline education has also seen significant growth. Traditional brick and mortar universities were initially reluctant to supplement their traditional curricula with online curricula. This reluctance is being overcome by the success of proprietary online educational institutions, which were expected to grow to $\$ 212$ billion in 2011 (Land and Bright, 2004). This success has fostered the rise in interest in online learning as other institutions look to achieve this same success in the growing online educational market (Craig, 2011).

It is also clear that team projects have been identified as important components in the delivery of online classes (Palloff \& Pratt, 1999; Williams \& Castro, 2010). However, business educators continue to struggle with how to create teams that encourage students to work collaboratively to solve problems (Goold \& Coldwell, 2008). Associated research (Hewson \& Hughes, 2005; McInnerney \& Roberts, 2004) supported the proposition that group interaction and lack of compatibility in virtual settings pose unique challenges and frustrations. Liu et al. (2008) suggested it would be useful to integrate cognitive styles as one of the factors in designing a course that fosters successful online virtual team experiences. 
There have been many studies reviewing the relationship of personality and team performance (Hewson \& Hughes, 2005; Kline \& O'Grady, 2009; McInnerney \& Roberts, 2004). However, their results have been inconsistent and inconclusive (Barry \& Stewart, 1997; Kline, 1999; Taggar, 2000; van Viennen \& De Drue, 2001; Yeatts \& Hyten, 1998) resulting in a lack of consensus. Some researchers have indicated that personality is a potential predictor of team performance (Potter \& Balthazard, 2002; Straus, 1996; Topi, et al., 2002; MacDonnell et al., 2009). Other research findings suggest a probable linkage between personality and team performance (Beise, et al., 2010; Chantal et al. (2010); Driskell et al., 1987; Faizuniah \& Chan, 2014; Hackman, 1975; Moreland \& Levine, 1992; Rutti et al., 2012), but their results are inconclusive. Current research indicates that there is a lack of research on successful team practices (Pinar et al., 2014).

There has been considerable work comparing the performance of face-to-face and virtual teams. Some researchers have found that virtual teams tend to be stronger than face-to-face teams related to group identity (Lea, Spears, \& deGroot, 2001) and group norms (Spears et al., 1990). Other studies have indicated that virtual teams have no performance advantage (Strauss and McGrath, 1994). However, while there would be value in comparing the impact of personality on face-to-face and virtual teams, this study focused on the impact of personality on virtual teams.

\section{LITERATURE REVIEW}

\section{Performance}

Over time, research has consistently indicated that groups fall short of reasonable performance baselines (Hill, 1982; Steiner, 1972). Steiner (1972) described this gap as process losses. Researchers have focused on identifying exceptions to the process loss phenomenon by identifying tasks and contexts where groups exceed their expected baseline. This has been approached by determining a productivity baseline based on the performance of the most capable group member, looking for the group to exceed the performance of the most capable member. Some researchers have reported group performance exceeding the most capable member baseline (Laughlin et al., 1995, 1998, 2003). Similar studies have reported group performance exceeding the performance of any one group member, or combination of group members, resulting in a desired bonus effect (Laughlin et al., 2002; Michaelsen et al., 1989; Phadnis \& Caplice, 2013; Sniezek \& Henry, 1989; Tindale \& Sheffey, 2002). However, these effects are typically minimal (Booth, 2011; Kerr \& Tindale, 2004) being related to the underestimation of a group's potential and the overestimation of the group's performance (Tindale \& Larson, 1992a, 1992b).

There have been several approaches to understand group process loss. One clear source of group process loss is the failure to identify and use the resources of effective group members (Kerr \& Tindale, 2004). A critical group task then becomes the ability to identify member expertise. Work has been done to determine cues for member expertise. One cue to assess member expertise is loquacity which was defined by Littlepage (Littlepage et al., 1995; Littlepage \& Mueller, 1995) as the ability of groups to use reason. Littlepage (Littlepage et al., 1995; Littlepage \& Mueller, 1995) also used confidence, influence and dominance as cues to assess team member potential. Collective behaviors of groups are found to impact group success (Kim et al., 2011; Drouin et al., 2010). Work conditions have also been studied as a factor in improving recognition of effective group members. Some conditions that have been studied are explicit directions to find the most capable group member (Henry, 1995), regular performance feedback (Henry et al., 1996), previous experience working together (Littlepage et al., 1997; Goodman \& Shah, 1992) and larger group size (Littlepage \& Silbiger, 1992). Researchers have also looked at memory as a feature related to how groups identify effective group members. Moreland (Moreland, 1999; Moreland \& Argote, 2003) have defined this as a transactive memory, an awareness of member competency. Transactive memory can be built by group training where group members learn about member competencies (Liang et al., 1995).

\section{Impact Of Personality On Performance}

MacDonnell et al. (2009) reported that personality has been considered a potential indicator of team performance (Grinnell et al., 2012; Hewson \& Hughes, 2005; Potter \& Balthazard, 2002; Straus, 1996; Topi et al., 2002). Findings have not been consistent and even contradictory resulting in uncertainty regarding the relationship of personality and performance (Barry \& Stewart, 1997; Kline, 1999; Taggar, 2000; van Viennen \& De Drue, 2001; 
Yeatts \& Hyten, 1998). Researchers have agreed that there is a likely connection between personality and team effectiveness (Driskell et al., 1987; Hackman, 1975; Jenster, 2010; Moreland \& Levine, 1992). O'Neil \& Kline (2008) reported a relationship between personality and team performance (Barrick et al., 1998; Brandstatter \& Farhofer, 1997; de Jong et al., 1999; Driskell et al., 1987). Personality traits have been associated with specific work behavior as a means of predicting team outcomes (McGrath, 1998; Honts et al., 2012; Hough \& Oswald, 2000).

Previous studies have operationalized team personality composition in terms of two characteristics: elevation and variation (Barrick et al., 1998; Kichuk \& Wiesner, 1998; Mohammed \& Angell, 2003; Neuman \& Wright, 1999; Peeters et al., 2006; Van Vianen \& De Dreu, 2001). In those correlational studies, elevation is predominately defined as the averaged or summed individual scores per trait and variation as the team's variance or standard deviation score per trait (Peeters et al., 2006). They also point out that trait elevation is calculated by the averaged or summed individual scores for a trait or by the proportion of high scoring individuals on a trait. Trait variability is represented by a team's variance or standard deviation score for a certain trait.

Peeters et al. (2006) conducted a meta-analysis on the relationship between personality and team performance based on the Big Five Inventory categories of Extraversion, Agreeableness, Conscientiousness, Emotional Stability and Openness to Experience. Their findings indicated that with both elevation and variation, Extraversion was not a factor with team performance. Agreeableness did appear to be a factor indicating that higher elevations led to higher performance. However, this effect was much more pronounced with professional teams than student teams. Higher average levels of Conscientiousness contributed to better performance. Elevations with Emotional Stability and Openness to Experience were also found to not correlate with increased team performance.

Varvel et al. (2004) reported no relationship between team average MBTI data and team effectiveness, which suggested that while personality may play a role in team performance; it is not predictive. The study did indicate that individuals who knew and understood their personality type (MBTI) helped them to improve their communication, interdependence and trust. Individuals' knowledge of each other's personality strengths and preferences facilitated effective communication, which enabled the team to capitalize on individual strengths (Cannon-Bowers et al., 1995). However, the utilization of personality factors to predict virtual team performance continues to be unclear (Topi et al., 2002).

Gardner and Martino (1996) reviewed the utilization of MBTI in management research questioning the relationship of personality types to profession. Caution was suggested when linking MBTI and work behavior based upon their extensive review of empirical literature reviewing correlation between MBTI and work behavior. They suggested the empirical data did not support the utilization of MBTI in this way. Other researchers have also questioned the utility of the MBTI related to career counseling (Bjork \& Druckman, 1991; Boyle, 1995). Although the MBTI is quite popular, it lacks the psychometric properties for empirically proven predictions (Pittinger, 2005)

\section{Insights Discovery Evaluator}

The IDE is based on the psychological type's theory of Dr. Carl Jung and Jolande Jacobi. Jung suggested that personality is the result of interaction of the two attitude traits (extroversion and introversion) and two function traits (thinking and feeling). Attitude traits describe an individual's orientation to the world and function traits describe an individual's mental processes (Jacques, et al., 2009). While attitude can be understood to be related to mood and be dynamic, Jung's use of attitude refers to a trait. Jung's use of the term function also refers to a trait. IDE presents this balance in terms of four colors, each a specific behavioral pattern as summarized in Figure 1 (Insights, 2014). A sample IDE Report can be reviewed at http://hrc.co.in/wp-content/uploads/2013/06/SampleInsights-Discovery.pdf

The IDE is listed on the British Psychological Society Psychological Testing Centre page under Test Registration and Test Reviews (http://www.psychtesting.org.uk/test-registration-and-test-reviews/test-reviews.cfm? page=summary\&Test_ID=99). The IDE was presented at the $11^{\text {th }}$ European Congress of Psychology (http://www.ecp2009.no/abstractview.cfm?pMode=AbstractView\&pAbstractId=11003) and has wide face validity as evidenced by its utilization in 25 languages. The IDE was used by 24,224 individuals between November, 2003 and July, 2004 in the UK alone (Benton et al, 2006) 
The University of Westminster's Business Psychology Centre completed a validity and reliability study of the IDE. Benton, et al., (2008) found that "of the 24,224 evaluators (completed between 31/11/2003 and 31/7/2004 in the UK) for each of the four colors in the evaluator, the average 'inter-item' correlation coefficient is significantly above 0.3, providing strong evidence of the case for reliability" (p. 22).They also found that the Cronbach-Alpha coefficient was approaching 1 and that there was construct validity using factor analysis, concurrent and predictive criterion validity.

The construct validity has been demonstrated through factor analysis and there is good predictive validity data by profession. These results all compare favorably with other Jungian-based instruments that are held in high regard by psychometricians and which also meet the standards set out by both the American Psychological Association and the British Psychological Society. "In summary, there is strong evidence to support the four-color measures calculated from the Insights Discovery model being both reliable and valid” (Benton et al., 2006, p 50).

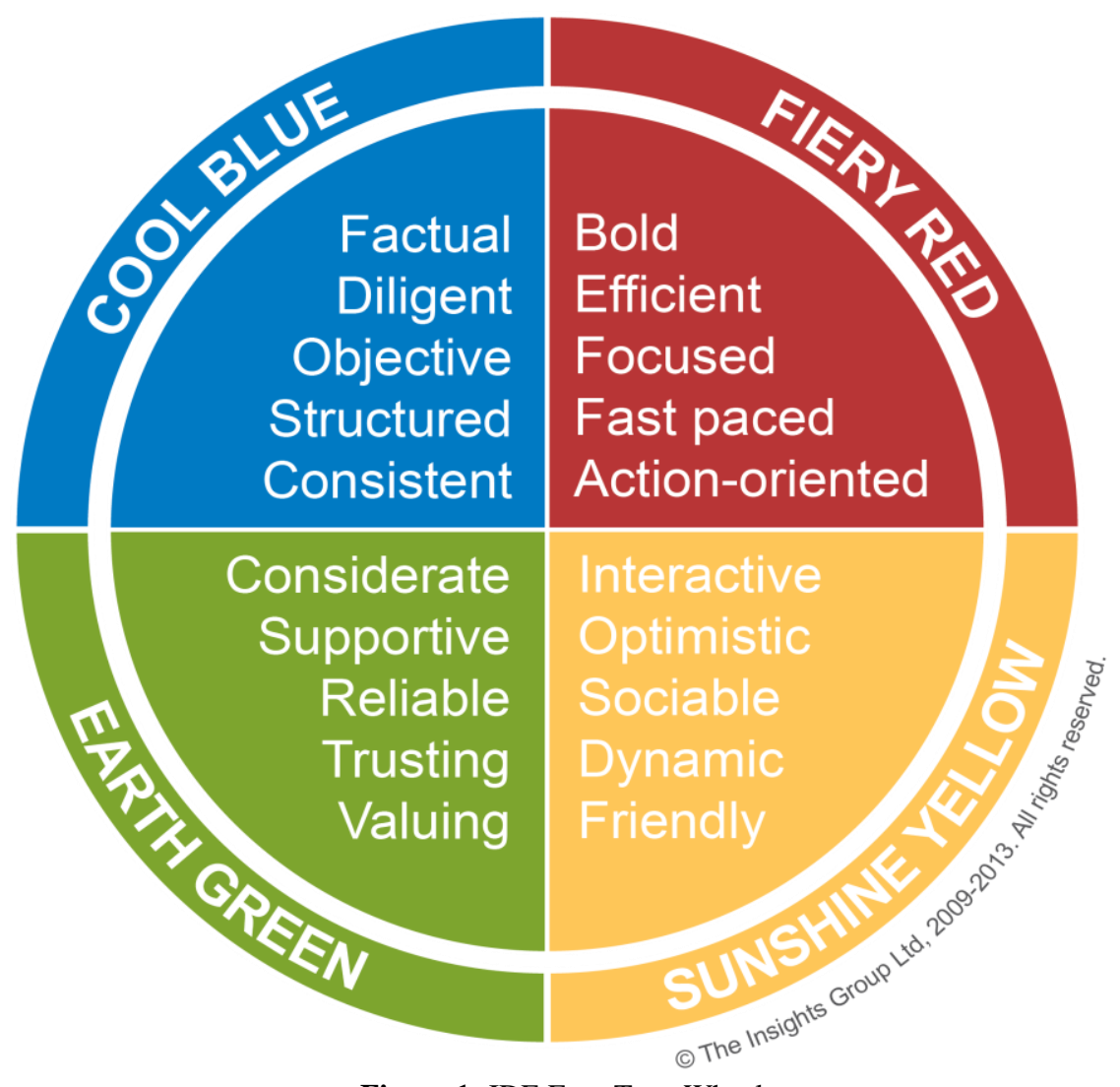

Figure 1: IDE Four Type Wheel

\section{Impact Of Cognitive Processes On Team Performance}

The IDE Jungian trait categories of attitude and function describe cognitive processes. Liu et al. (2008) pointed out that there had been minimal work reviewing the relationship of cognitive processes and virtual team performance. Sternberg proposed a correlation between work environment and cognitive thinking style (1997). Individuals perform better when placed in a work environment that matches their cognitive thinking style (Mukherjee et al., 2012). Hayes and Allison (1998) pointed out that local people may prefer work environments that have access to data and the time to process that data while global people may not need this base knowledge to be creative. Other researchers have reported that cognitive processes were not a factor in virtual team performance (Lui, 2012; Kim et.al., 2011). 
Many studies regarding the role of cognitive style in team work performance have focused on traditional workplaces. Less research has been conducted on the relationship between cognitive process and virtual team performance. Workman et al. (2003) found that in virtual work environments, people with external styles who prefer group interactions had a higher commitment to virtual team work than those without such styles. CunninghamAtkins and his associates (2004) found that in a computer mediated group discussion online, the teams with a greater diversity of cognitive styles outperformed less diversified teams. There is also empirical evidence to support the linkage of cognitive style and work environment for improved team performance. Individuals whose cognitive styles align with the competencies needed have increased satisfaction (Cunningham-Atkins et al., 2004; Hayes \& Allinson, 1998).

\section{Impact Of Bias On Team Performance}

Convertino (2008) stated that individual bias was a factor in team performance. Team bias is based on the persistence of individual bias found in team members. Homogeneous groups were more biased than heterogeneous groups. Increasing group diversity decreases bias and increases team performance (Schult-Hart et.al., 2000). Tolcott et al. (1989) demonstrated the tendency of expert intelligence analysts to prefer information given at the start of the scenario disregarding subsequent information that changed the overall weight of information. Another source of bias is the product of group processes (Kerr \& Tindale, 2004). Team members with a minority view are less likely to be heard and their information considered, even if the information is critical. Gigone and Hastie (1996) described this as the common knowledge effect. These biases erode the potential value of bringing together a diversity of knowledge and skills. Team performance is likely to be improved with increased diversity resulting in more shared knowledge and perspective (van Knippenberg \& Schippers, 2007). However, too much diversity can require large initial investments in building common ground, which may diminish team performance (Convertino, 2008).

\section{Team Model}

The input-process-output model (IPO) is a widely accepted model for understanding team effectiveness (Driskell et al., 1987). The IPO model suggests that input (individual, environmental and group level factors) and process (e.g., communication, conflict) affect team output (Barrick et al., 1998). This paper uses the IPO model as a frame for understanding the impact of personality on team performance (see Figure 2).

\section{RESEARCH METHOD}

\section{Hypotheses}

H1 $1_{\mathrm{A}}$ : Teams with a majority of members with the Cognitive Trait Attitude of Extroversion (IDE Red and Yellow types) have a greater probability to perform better than teams with a majority of members with the Cognitive Trait Attitude of Introversion (IDE Blue and Green types).

H2 ${ }_{\mathrm{A}}$ : Teams with a majority of members with the Cognitive Trait Function of Thinking (Blue and Red types) have a greater probability to perform better than teams with a majority of members having the Cognitive Trait Function of Feeling (IDE Green and Yellow types).

$\mathbf{H 3}_{\mathrm{A}}$ : Teams with a majority of members having a Red IDE type have a greater probability to perform better than teams with a majority of members having the Yellow IDE type, Green IDE type or Blue IDE type Blue.

$\mathbf{H 4}_{\mathrm{A}}$ : Teams with lower bias (teams with all four IDE types) have a greater probability to perform better than teams with higher bias (teams with one dominant IDE type).

\section{Approach}

The study utilized a general mixed methods research methodology. Pairs of researchers collected qualitative data reviewing a team assignment transcript where students reported their IDE type. The qualitative data were as not entered until there was full consensus with each pair regarding assignment of IDE type to each student. Those teams where one or more team members did not indicate their IDE type, or the researchers could not determine their IDE type, were excluded from the study. Each researcher received IDE training. One researcher was an IDE certified instructor who served as final arbitrator. Quantitative data were collected in the form of numerical grades (performance) on team assignments and reviewed using descriptive statistics, t-tests and ANOVA testing. 


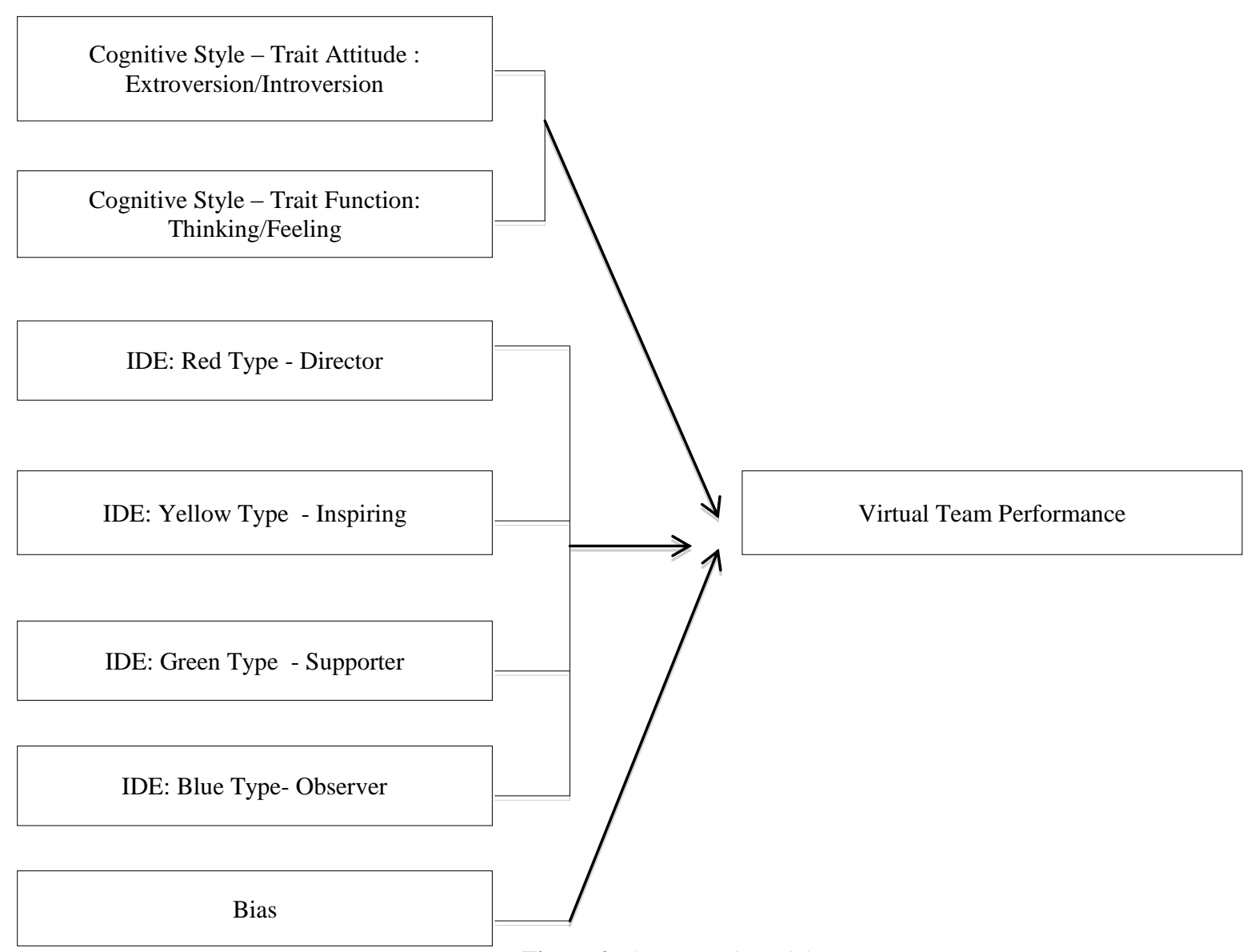

Figure 2: Conceptual Model

The Jungian Cognitive Trait Attitude (Extroversion/Introversion) was identified as with the left/right quadrants as IDE Green and Blue being Introversion and the IDE Red and Yellow being Extroversion (see Figure 3). The Jungian Cognitive Trait Function (Thinking/Feeling) was identified with the upper and lower quadrants IDE Blue and Red being Thinking and the IDE Green and Yellow being Feeling (see Figure 4). 


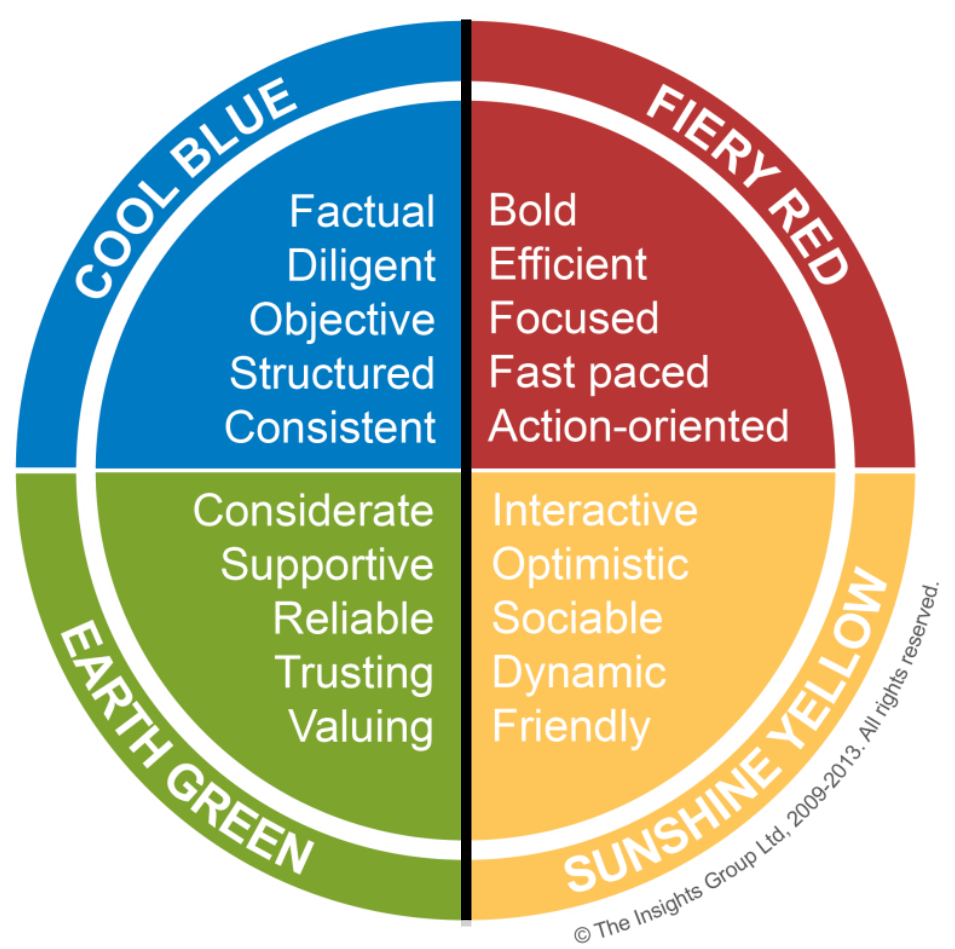

Figure 3: IDE Wheel Displaying Trait Attitude: Extroversion (Red/Yellow) And Introversion (Blue/Green)

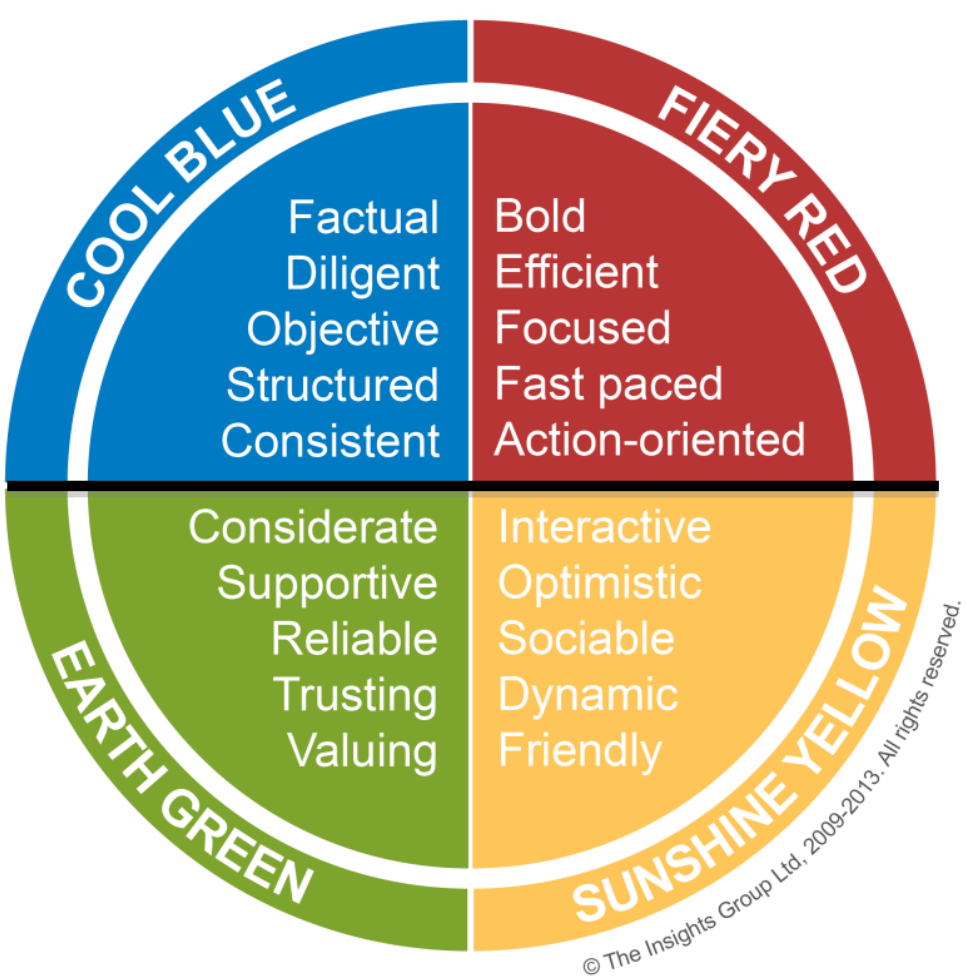

Figure 4: IDE Wheel Displaying Trait Function: Thinking (Blue/Red) And Feeling (Green/Yellow) 


\section{Measures}

While previous literature on personality has utilized Personality Elevation and Team Personality Variability (Neuman \& Wright, 1999), given the parameters of this study, nominal data were used to determine team groupings. Teams with a majority of the members having one IDE type and any other IDE type represented by less than 50\% of the team members were designated as Dominant. Teams where at least one of the IDE types was missing on the team were designated as Random. Teams where each of the primary IDE types were on the team were designated Variable. Bias was ranked as Dominant teams having the highest bias and Variable as having the lowest bias (see Table 1).

- $\quad$ Dominant (D) - Teams where 50\% or more of the subjects had the same primary IDE type, resulting in Dominant Red, Blue, Yellow or Green teams

- $\quad$ Variable $(\mathrm{V})$ - Teams where subjects from each of the primary IDE types (Red, Blue, Yellow, and Green) were on the team

- $\quad$ Random (R) - Teams where at least one of the primary IDE types (Red, Blue, Yellow, or Green) was missing on the team

Table 1: Team Personality Type (TPT) Example

\begin{tabular}{lcccccc}
\hline Team Example & Student 1 & Student 2 & Student 3 & Student 4 & Student 5 & Team Personality Type (TPT) \\
Team A & \#Red & \#Red & \#Red & Blue & Yellow & \#Dominant Red \\
Team B & \#Blue & \#Blue & \#Blue & Red & Yellow & \#Dominant Blue \\
Team C & \#Red & \#Blue & \#Yellow & \#Green & Green & \#Variable \\
Team D & Red & Red & Blue & Blue & Green & \#Random (no Yellow) \\
\hline
\end{tabular}

General Note: This example shows the three possible team color combinations. Team D was missing a student with a "Yellow" color energy so it would be identified as a Random team.

\section{Sample And Performance}

Subjects were students who completed the first six-week MBA online course between the years of 2010 and 2012 in a proprietary university. Some students were new to online education and others were not. The sample consisted of 71 classes involving 1,800 student-learning teams. One hundred and thirty-eight of those teams were included in the study. Teams that had fewer than four, or more than six, members were excluded from the study. Any team with an incomplete IDE record, or where one or more of the members did not disclose their IDE or their IDE could not be determined, were also excluded from the study.

Students were assigned to teams of up to six students by the course instructor and completed three team assignments during the six-week course. These three assignments formed the one aggregate performance score used as the dependent performance variable. Assignment One (see Appendix A) required team members to exchange information about their particular strengths, fields of study, and work experience. Working collaboratively, this information was used to compose a memo addressed to the instructor and the class (approximately 500-600 words), introducing the team and reviewing their team strengths and challenges. The finished team memo also included an assessment of the team's style using each members' IDE information.

Assignment Two (see Appendix B), graded in week five of the six-week course, was the culmination of a team project that ran throughout the term. It focused on a market simulation assignment. Each student's team project score was based on peer evaluations and the team's success in the business simulation, including variables such as total demand, stock outs, emergency loans, bankruptcy, net income, ending cash flow, retained earnings, and balanced scorecard. At the end of simulation, there was a "Cumulative Balanced Scorecard" for each team based on their simulation performance.

Assignment Three (see Appendix C) was a PowerPoint presentation in week six of the six-week course summarizing their Market Simulation strategy and outlining where the team believes their simulated company should go next. The presentation reviewed future sales, marketing, expansion, research and development, future cash flow, and bottom line. 


\section{RESULTS}

\section{Descriptive Statistics}

The descriptive statistics of the Team Personality Type (TPT) combinations for all teams included in the study are shown in Table 2. All variables had reasonable psychometric properties including normal distribution, relatively equal standard deviations, and population independence. Eighty-four teams identified as having a Dominant TPT (50\% of the team had the same Insight type) had a mean composite assignment score (all three assignments) of 91.69 (out of 100) and a standard deviation of 4.26; twenty teams identified as having a Variable TPT (team had all four of the Insight types represented) had a mean composite assignment score of 89.91 and a standard deviation of 5.49; thirty-four teams identified as having a Random TPT (at least one of the primary IDE types was missing) had a mean composite assignment score of 90.54 and a standard deviation of 4.80 . The entire sample of 138 participants had an overall mean score on all three assignments of 91.12 and a standard deviation of 4.61 .

Table 2: Descriptive Statistics

\begin{tabular}{lcccc}
\hline \multicolumn{1}{c}{ Statistic } & $\begin{array}{c}\text { Dominant } \\
\text { Color Combo }\end{array}$ & $\begin{array}{c}\text { Variable } \\
\text { Color Combo }\end{array}$ & $\begin{array}{c}\text { Random } \\
\text { Color Combo }\end{array}$ & $\begin{array}{c}\text { All Study } \\
\text { Participants }\end{array}$ \\
\hline Mean & 91.69 & 89.91 & 90.542 & 91.12 \\
Standard Error & 0.46 & 1.23 & 0.82 & 0.39 \\
Median & 92.92 & 91.17 & 90.44 & 91.94 \\
Mode & 93.71 & $\mathrm{n} / \mathrm{a}$ & 94.08 & 94.08 \\
Standard Deviation & 4.26 & 5.49 & 4.80 & 4.61 \\
Sample Variance & 18.17 & 30.17 & 23.03 & 21.21 \\
Kurtosis & 0.24 & -0.26 & -0.39 & -0.11 \\
Skewness & -0.77 & -0.14 & -0.58 & -0.63 \\
Range & 19.54 & 20.76 & 18.31 & 20.76 \\
Minimum & 79.46 & 78.80 & 79.61 & 78.80 \\
Maximum & 99.00 & 99.56 & 97.92 & 99.56 \\
Sum & 7698.52 & 1798.13 & 3078.42 & 12575.08 \\
Count & 84 & 20 & 34 & 138 \\
\hline
\end{tabular}

General Note: Descriptive statistics for the three color combination groups being compared in this study

\section{Hypotheses $\mathrm{H} 1$ and $\mathrm{H} 2$}

The hypotheses in this study posited that team personality composition has an effect on team performance.

H1 $1_{\mathrm{A}}$ : Teams with a majority of members with the Cognitive Trait Attitude of Extroversion (IDE Red and Yellow types) have a greater probability to perform better than teams with a majority of members with the Cognitive Trait Attitude of Introversion (IDE Blue and Green types).

$\mathbf{H 2} \mathbf{A}_{\mathrm{A}}$ : Teams with a majority of members with the Cognitive Trait Function of Thinking (Blue and Red types) have a greater probability to perform better than teams with a majority of members having the Cognitive Trait Function of Feeling (IDE Green and Yellow types).

An EXCEL "t Test: Two Sample Assuming Equal Variance" procedure was used to evaluate hypotheses $\mathrm{H} 1_{\mathrm{a}}$ and $\mathrm{H} 2_{\mathrm{a}}$. No significant difference was found in the aggregate team scores between teams with either of the Cognitive Attitudes or Functions. The Cognitive Attitude Trait Extroversion teams (Red/Yellow) did not perform differently than the Cognitive Attitude Trait Introversion teams (Hypothesis 1). The Cognitive Function Trait Thinking teams did not perform differently than the Cognitive Function Trait Feeling teams (Hypotheses 2).

The differences between the average aggregate team scores of teams with a majority of Cognitive Trait Attitude Extroversion or Introversion and teams with a majority of Cognitive Trait Function Thinking or Feeling Cognitive Trait Attitude are displayed in Table 3. Using a .05 level of confidence, no statistically significant difference $(\mathrm{P}=0.363)$ was found between the aggregate team scores of teams with a majority of Extroversion $($ Red/Yellow; Mean $=92.27)$ and a majority of Introversion $($ Blue/Green; Mean $=91.36)$ personality types. Likewise, comparing the average aggregate team scores of teams with a majority of Thinking (Red/Blue; Mean 
$=91.67)$ to teams with a majority of Feeling $($ Green/Yellow; Mean $=91.56)$ also resulted in a lack of statistical significance at the .05 level of confidence $(\mathrm{P}=0.903)$.

Table 3: t-Test: Two Sample Assuming Equal Variance -

Comparison of Cognitive Attitudes and Function Using Aggregate Team Assignment Scores

\begin{tabular}{lcccc}
\hline \multirow{2}{*}{ Statistic } & \multicolumn{2}{c}{ Cognitive Trait Attitudes } & \multicolumn{2}{c}{ Cognitive Trait Functions } \\
\cline { 2 - 5 } & $\begin{array}{c}\text { Extroversion } \\
\text { Red/Yellow }\end{array}$ & $\begin{array}{c}\text { Introversion } \\
\text { Blue/Green }\end{array}$ & $\begin{array}{c}\text { Thinking } \\
\text { Blue/Red }\end{array}$ & $\begin{array}{c}\text { Feeling } \\
\text { Green/Yellow }\end{array}$ \\
\hline Mean Team Scores & 92.27 & 91.36 & 91.67 & 91.56 \\
Variance & 14.31 & 20.01 & 17.21 & 21.25 \\
Observations & 27 & 57 & 59 & 25 \\
Pooled Variance & 18.20 & & 18.39 & 82 \\
Df & 82 & & 1.222 & 0.903 \\
t Stat & 0.914 & & 1.989 & \\
P(T<=t) two-tail & 0.363 & & & \\
t Critical two-tail & 1.989 & &
\end{tabular}

\section{Hypothesis 3}

$\mathbf{H 3}_{\mathrm{A}}$ : Teams with a majority of members having a Red IDE type have a greater probability to perform better than teams with a majority of members having the Yellow, Green or Blue IDE type.

To assess H3a, a One-Way Analysis of Variance (ANOVA) procedure was applied to determine differences between average aggregate team scores from teams where the dominant type was Red, Green, Yellow or Blue. Levene's test for homogeneity showed equality of variances in the samples with no significant skewness or kurtosis. The results in Table 4 show there was no significant $(P=0.439)$ difference between teams in comparing the average composite team scores for the four personality types. All four IDE types performed equally as well.

Table 4: ANOVA: Comparison of Personality Types Using Average Team Assignment Scores

\begin{tabular}{lccccc}
\hline \multicolumn{1}{c}{ Personality Type } & Count & Sum & $\begin{array}{c}\text { Mean Team } \\
\text { Scores }\end{array}$ & Variance \\
\hline IDE Red-Director & 20 & 1856.94 & 92.85 & 12.313 \\
IDE Green-Supporter & 18 & 1654.76 & 91.93 & 22.889 & \\
IDE Yellow-Inspiring & 7 & 634.278 & 90.61 & 18.696 & \\
IDE Blue-Observer & 39 & 3552.54 & 91.09 & 19.025 & Significance \\
\hline \multicolumn{1}{c}{ Team Performance } & Sum of Squares & Df & Mean Square & F & 0.439 \\
\hline Between Groups & 49.833 & 3 & 16.611 & .911 & 18.228 \\
Within Groups & 1458.189 & 80 & & & \\
\hline
\end{tabular}

\section{Hypothesis 4}

$\mathbf{H 4}_{\mathrm{A}}$ : Teams with lower bias (teams with all four IDE types) have a greater probability to perform better than teams with higher bias (teams with one dominant IDE type).

A "t Test: Two Sample Assuming Equal Variance" procedure was again used to evaluate hypotheses $\mathrm{H} 4_{\mathrm{a}}$. Teams were ranked in terms of bias with Dominant teams being highly biased and Random teams being less biased (see Table 3). While this hypothesis showed the most difference between teams, it was not statistically significant. The differences between the average aggregate team scores based on bias are displayed in Table 5. Using a .05 level of confidence, no statistically significant difference $(\mathrm{P}=0.124)$ was found between the aggregate team scores of teams with higher and lower bias. 
Table 5: t-Test: Two Sample Assuming Equal Variance -

Comparison of Bias Team Personality Type Using Composite Team Assignment Scores

\begin{tabular}{|c|c|c|}
\hline \multirow{2}{*}{ Statistic } & \multicolumn{2}{|c|}{ High Bias Compared To Low Bias } \\
\hline & High Bias & Low Bias \\
\hline Mean Team Scores & 91.65 & 89.91 \\
\hline Variance & 18.17 & 30.17 \\
\hline Observations & 84 & 20 \\
\hline Pooled Variance & 20.41 & \\
\hline df & 102 & \\
\hline t Stat & 1.551 & \\
\hline $\mathrm{P}(\mathrm{T}<=\mathrm{t})$ two-tail & 0.124 & \\
\hline t Critical two-tail & 1.983 & \\
\hline
\end{tabular}

General Note. Failure to reject the null hypothesis at two-tail $\mathrm{P}=.05$ level of confidence

\section{DISCUSSION}

This study examined the impact of cognitive trait style, personality type and bias on virtual team performance (see the Conceptual Model in Figure 2). This study anticipated a correlation between personality type and team performance; however, the IDE did not indicate any correlation between personality type and team performance, which paralleled the mixed research findings in this area. The inputs in the conceptual team model presented in Figure 2 related to Cognitive Attitude Trait (Extroversion-Red/Yellow and Introversion-Blue/Green) and Cognitive Function Trait (Thinking-Red/Blue and Feeling-Green/Yellow) as well as the four types of the IDE did not have an impact on team performance. Like Liu and $\mathrm{Li}$ (2012), this study did not find cognitive style to be an indicator of virtual team performance.

Bias also did not appear to be a factor in team performance. Several sources in the literature review suggested that bias would be a factor in team performance. Homogeneous groups prefer processes and solutions driven by their dominant characteristics. Heterogeneous groups will be more diverse, less inclined to bias, preferred processes and solutions, resulting in improved team performance. While this has face validity, this study did not find a difference between groups with the factor of bias. The greatest difference between groups in the study was on the bias factor; however, the difference was not statistically significant.

Effective leadership is not defined by any particular IDE type grouping. To assume, for example, that the Red-Director type was uniquely qualified to lead is not reinforced by this study. There was no statistical difference between teams that were Dominant with a 50\% majority of Red, Blue, Yellow, or Green. All four performed equally as well. There is value in eliminating preconceived ideas about individual personality types related to team performance or leadership.

Although this study did not find a statistically significant relationship between any of the team IDE type combinations, Cognitive Thinking Trait and bias, it should not dissuade educators and leaders from considering team personality makeup as a factor in team effectiveness and performance. On the contrary, it is known from previous studies that areas such as individual agreeableness and extraversion are positively related to team performance (Kline \& O'Grady, 2009). Limitations of the study are addressed in the following "Future Research" section.

Online educators will continue to want to position their online student teams for success. Temporal variables related to time and space may have a larger impact than personality type. While utilization of the IDE may facilitate increased self-understanding and group communication, this potential process gain would be shared equally.

\section{FUTURE RESEARCH}

Subsequent research in this area could be strengthened in several ways. A larger and more generalized sample (and not all from one course) would provide more results on which to base conclusions. Grade inflation should be addressed as a moderating factor. The majority of teams earned an "A" on all assignments. This inflation 
may have masked any differences in team performance. A grade distribution indicating normal distribution may have yielded different results.

The study was also limited to nominal data. Utilization of personality elevation and variability would have added great value. Further, additional detail within the IDE data is highly recommended to establish connections between specific IDE types and team performance outcomes. The IDE has 64 personality types. The study was limited to the four primary personality types and not able to review the 16 personality types in each of the four. There may have been correlations of personality and virtual team performance with the granular 64 personality types that were missed with the broad four used in the study. Combining qualitative or using mixed methodology approaches may also offer a more rounded view of the subject matter.

While the IDE is widely used in corporate and leadership environments, like MBTI it lacks sufficient psychometric robustness to predict behavior. Further, the psychometric validity of the IDE needs additional development. There have not been sufficient independent academic studies to validate the assessment.

The researchers noticed a difference in team performance related to personality by task complexity. While the aggregate team scores lacked difference, there did appear to be some difference between teams related to task complexity. Some types of work may be better addressed by one personality type than another. A review of work taxonomy related to personality and performance may yield additional insight on the relationship of personality to virtual team performance. The proposed conceptual team model presented in Figure 2 may be more relevant if the dependent variable of virtual team performance is defined by task complexity. The researchers will pick this up as their next study.

\section{AUTHOR INFORMATION}

Joel Olson has a PhD in Human Resources from Colorado State University, Ft. Collins and an MA in theology from Denver Seminary. He has extensive experience in nonprofit leadership and consultation, education, and instructional design. Most recently, he has served the Reformed Church in America and the Evangelical Presbyterian Church as a consultant for churches in crisis. Currently, he serves as the Leadership and Management Academic Department Chair for the School of Business and Management in Kaplan University. Email: jolson@kaplan.edu.

Darlene Ringhand, Ph.D. in Business Administration with a focus on Information Systems from Northcentral University. Master of Science from Utah State University in Business and Information Systems. Work experience includes on-ground at University of Rio Grande serving as Associate Professor and Department Chair; Colorado Northwestern Community College as Faculty and Department Chair; and, currently, online as Associate Professor for DeVry University and Keller Graduate School of Management. Prior teaching experience with Kaplan, Ashford and Strayer Universities. Owner of two small businesses and active with Quality Matters as a Master Reviewer. Email: dringhand@devry.edu.

Ray Kalinski has a $\mathrm{PhD}$ in Organization and Management and has taught in the MBA program at Kaplan University for about seven years. His Masters is in Counseling and Guidance from the University of Nebraska at Omaha. His professional background ranges from public agency and nonprofit management to extensive experience in the Aerospace industry where he held positions in Information System's management, Project Management, and Business Operations. Email: rkalinski@kaplan.edu.

James Ziegler, PhD has taught in the MBA program at Kaplan University and the PhD program at University of Phoenix. Email: jziegler@kaplan.edu.

\section{REFERENCES}

Barrick, M. R., Stewart, G. L., Neubert, M. J., \& Mount, M. K. (1998). Relating member ability and personality to work-team processes and team effectiveness. Journal of Applied Psychology, 83, 377-391.

Barry, B., \& Stewart, G. L. (1997). Composition, process, and performance in self-managed groups: The role of personality. Journal of Applied Psychology, 82, 62-78. 
Beise, Catherine, Carte, Traci, Vician, Chelley, \& Chidambaram, Laku. A case Study of Project Management Practices in Virtual Settings: Lessons from Working in and Managing Virtual Teams. Database for Advances in Information Systems 41.4 (Nov 2010): 75-97.

Benton, S., van Erkom Schurink, C., \& Desson, S. (2008). An executive Summary of the Development, Validity and Reliability of the English Version 3.0 of the Insights Discovery Evaluator. University of Westminster.

Benton, S., van Erkom Schurink, C., \& Desson, S. (2006). An overview of the development, validity, reliability and reliability of the English Version 3.0 on the Insights Discover Evaluator. Project Report. KTP, DTI, UK. (Unpublished).

Bjork, R. A., \& Druckman, D. (1991). In the mind's eye: Enhancing human performance. Washington, DC: National Academy Press.

Booth, B. (2011). Examining the Critical Factors of Success in Virtual Team Performance. (Doctoral Dissertation). Available from ProQuest Dissertations and Theses database. (UMI 3442987).

Boyle, G. J. (1995). Myers-Briggs Type Indicator (MBTI): Some psychometric limitations. Australian Psychologist, 30, 71-74.

Brandstatter, H., \& Farthofer, A. (1997). Personality in social influence across tasks and groups. Small Group Research, 28, 146-163.

Cannon-Bowers, J., Tannenbaum, S., Salas, E., \& Volpe, C. (1995). "Defining competencies and establishing team training requirements." In Team effectiveness and decision making in organizations, Eds. R. A. Guzzo and E. Salas, 333-380, Jossey-Bass, San Francisco.

Chantel, M. J. H., Beatrice, I. J. M., \& Peoll, R.F. (2010). Attitudes towards factors influencing team performance: A multi-rater approach aimed at establishing the relative importance of team learning behaviors in comparison with other predictors of team performance, Team Performance Management, 16(7/8). 451-474.

Convertino, M. P. (2008). The CACHE Study: Group Effects in Computer Supported Cooperative Work. 17(10), 353-393.

Craig, J. E. (2011). Uncovering and analyzing potential gaps in teaching graduate programs in leadership by way of online education. (Doctoral Dissertation). Available from ProQuest Dissertations and Theses database (UMI 3479084).

Cunningham-Atkins, H., Powell, N., Moore, D., Hobbs, D., \& Sharpe, S. (2004). The Role of Cognitive Style in Educational Computer Conferencing. British Journal of Educational Technology, 35 (1) 69-80.

de Jong, R. D., Bouhuys, S. A., \& Barnhoorn, J. C. (1999). Personality, self-efficacy and functioning in management teams: A contribution to validation. International Journal of Selection and Assessment, 7, 46-49.

Driskell, J. E., Hogan, R., \& Salas, E. (1987). "Personality and group performance.” In Review of Personality and Social Psychology, Ed. C. Hendrick, 91-112. Newbury Park, CA: Sage.

Drouin, Nathalie, Bourgault, Mario, \& Gervais, Caroline. (2010). Effects of organizational support on components of virtual project teams. International Journal of Managing Projects in Business, 3.4, 625-641.

Faizuniah, P., \& Chan, J. M. (2014). The mediating effect of knowledge sharing on the relationship between trust and virtual team effectiveness. Journal of Knowledge Management, 18(1). 92-106.

Gardner, W. L., \& Martinko, M. J. (1996). Using the Meyers-Briggs Type Indicator to study managers: A literature review and research agenda. Journal of Management, 22, 45-8.

Gigone, D., \& R. Hastie. (1996). The Impact of Information on Small Group Choice. Journal of Personality and Social Psychology, 72,132-140. doi:10.1037/0022-3514.72.1.132.

Goold, A., Craig, A., \& Coldwell, J. (2008). The student experience of working in teams online. Paper presented at the 2008 Ascilite Melbourne Conference Retrieved November 5, 2011 from http://www.ascilite.org.au/conferences/melbourne08/procs/goold.pdf .

Goodman, P. S., \& Shah S. (1992). Familiarity and work group outcomes. In Group Process and Productivity, Eds. S. Worchel, W. Wood, \& J. A. Simpson, pp. 276-98. Newbury Park, CA: Sage.

Grinnell, Lynn, Sauers, Amy Appunn, Frank, \& Mack, Larry. (2012).Virtual teams in Higher Education: The light And Dark Side. Journal of College Teaching \& Learning (Online) 9.1, 65.

Hackman, J. R. (1975). Group influences on individuals. In Handbook of Industrial and Organizational Psychology. Ed. M. D. Dunnette, Chicago, IL: Rand-McNally.

Hayes, J., \& Allinson, C. W. (1998). Cognitive Style and theory and Practice of Individual and Collective learning in Organizations. Human Relations, 51 (7), 847-871. 
Henry, R. A. (1995). Improving group judgment accuracy: information sharing and determining the best member. Organizational Behavior and Human Decision Process, 62(2), 190-97.

Henry, R. A., Strickland, \& O. J., Yorges, S. L., \& Ladd, D. (1996). Helping groups determine their most accurate member: the role of outcome feedback. Journal of Applied Social Psychology, 26(13):1153-70.

Hewson, L., \& Hughes, C. (2005). Social processes and pedagogy in online learning. Association for the Advancement of Computing in Education Journal, 13(2), 99-125.

Hill, G. W. (1982). Group versus individual performance: Are N C1 heads better than one? Psychological Bulletin. 91:517-39.

Honts, C., Prewett, M., Rahael, J., \& Grossenbacher, M. (2012). The importance of team processes for different team types. Team Performance Management 18, 5/6, 312-327.

Hough, L. M., \& Oswald, F. L. (2000). Personnel selection: Looking toward the future-remembering the past. Annual Review of Psychology, 51, 631-664.

Insights. (2014) Validating the System. Retrieved from http://www.insightscalgary.com/our_tools/Discovery\%20Validating\%20the\%20System\%20Factsheet.pdf.

Jacques, G. B., Garger, J., Brown, C. A., \& Deale, C. S. (2009). Personality and Virtual Reality Team Candidates: The Roles of Personality Traits, Technology Anxiety and Trust as Predicators of Perceptions of Virtual Reality Teams. Journal of Business Management, 15(2),143-157.

Jenster, N. P. (2010). Leadership Impact on Motivation, Cohesiveness and Effectiveness in Virtual Teams: A FIRO Perspective. Grenoble Ecole de Management (France), ProQuest, UMI Dissertations Publishing, 3471610.

Kerr, N. L., \& Tindale, S. R. (2004). Group Performance and Decision Making. Annual Review of Psychology, vol. 55, pp. 623-65 doi:10.1146/annurev.psych.55.090902.142009.

Kichuk, S. L., \& Wiesner, W. H. (1998). Work teams: Selecting members for optimal performance. Canadian Psychology, 39, 23-32.

Kim, Paul, Lee, Donghwan, Lee, Youngio, Huang, Chuan, \& Makany, Tamas. (2011). Collective intelligence ration: Measurement of real-time multimodal interactions in team projects. Team Performance Management, (17), $1 / 2,41-62$.

Kline, T. J. B. (1999). Remaking teams: The revolutionary research based guide that puts theory into practice. San Francisco: Jossey-Bass.

Kline, T., \& O’Grady, J. K. (2009). Team member personality, team processes, and outcomes: Relationships within a graduate student project team sample. North American Journal of Psychology, 11(2), 369-382.

Land, T., \& Bright, T. (2004). The distant learning leader: What you don't know could hurt you. Distance learning, 1, 24-32.

Laughlin, P. R., Chandler, J. S., Shupe, E. I., Magley, V. J., \& Hulbert, L. G. (1995). Generality of a theory of collective induction: Face-to-face and computer-mediated interaction, amount of potential information, and group versus member choice of evidence. Organizational Behavior and Human Decision Process, 63, 98111.

Laughlin, P. R., Bonner, B. L., \& Miner, A. G. (2002). Groups perform better than the best individuals on Letters-to-Numbers problems. Organizational Behavior and Human Decision Process, 88(2), 605-620.

Lea. M., Spears, R., \& deGroot, D. (2001). Knowing me, knowing you: Anonymity effects on social identity processes within groups. Personality and Social Psychology Bulletin, 27, 526-37.

Liang, D. W., Moreland, \& R. L., \& Argote, L. (1995). Group versus individual training and group performance: The mediating factor of transactive memory. Personality and Social Psychology Bulletin, 21(4), 384-93.

Littlepage, G. E., \& Silbiger, H. (1992). Recognition of expertise in decision-making groups: effects of group size and participation patterns. Small Group Research, 23(3), 344-55.

Littlepage, G. E, Schmidt, G. W., Whisler, E. W., \& Frost, A. G. (1995). An input-process-output analysis of influence and performance in problem solving groups. Journal of Personality and Social Psychology, 69(5), 877-89.

Littlepage, G. E., \& Mueller, A. L. (1997). Recognition and utilization of expertise in problem solving groups: Expert characteristics and behavior. Group Dynamics, 1(4), 324-28. 
Liu, P. L., \& Li, Z. (2012). Task complexity: a review and conceptualization framework. International Journal of Industrial Ergonomics, 42, 553-568.

Liu, X., Magjuka, R. J., \& Lee. S. (2008). The effects of cognitive thinking styles, trust, conflict management on online students' learning and virtual team performance. British Journal of Educational Technology, 39(5), 829-846.

MacDonnell, R., O’Neill, T., Kline, T., \& Hambley, L. (2009). Bringing group-level personality to the electronic realm; A comparison of face-to-face and virtual contexts. The Psychologist-Manger Journal 12,1-24. DOI: $10.1080 / 10887150802371773$.

McGrath, J. E. (1998). A view of group composition through a group-theoretic lens. In Research on Managing Groups and Teams Volume 1, Eds. M. A. Neale, E. A. Mannix, \& D. H. Gruenfeld, 255-272. Stamford, CT: JAI Press Inc.

McInnerney, J. M., \& Roberts, T. S. (2004). Online learning: Social interaction and the creation of a sense of community. Educational Technology \& Society, 7(3), 73-81.

Michaelsen, L. K., Watson, W. E., \& Black, R. H. (1989). A realistic test of individual versus group consensus decision making. Journal of Applied Psychology. 74, 834-39.

Mohammed, S., \& Angell, L. C. (2003). Personality heterogeneity in teams: Which differences make a difference for team performance? Small Group Research, 34, 651-677.

Moreland, R. L., \& Levine, J. M. (1992). Problem identification by groups. In Group Process and Productivity. Eds. S. Worshel, W. Wood \& J. A. Simpson, 17-47. New York: Sage.

Moreland, R. L. (1999). Transactive memory. In Learning Who Knows What in Work Groups and Organizations, Eds. L. Thompson \& J. Levine, 3-31. Mahwah, NJ: Erlbaum.

Moreland, R. L., \& Argote, L. A. (2003). Transactive memory in dynamic organizations. In Leading and Managing People in the Dynamic Organization. eds. R. S. Peterson \& E. A. Mannix, 135-162, Mahwah, NJ: Erlbaum.

Mukherjee, D., Lahiri, S., Mukherjee, D., \& Billing, T. K. (2012). Leading virtual teams: how do social, cognitive, and behavioral capabilities matter? Management Decision, 50(2), 273-290.

Neuman, G. A., \& Wright, J. (1999). Team effectiveness: Beyond skills and cognitive ability. Journal of Applied Psychology, 84, 376-389.

O’Neill, T., \& Kline, T. (2008). Personality as a predictor of teamwork: A business simulator study. North American Journal of Psychology, 10(1), 65-78.

Palloff, R. M, \& Pratt, K. (1999). Building learning communities in cyberspace: Effective strategies for the online classroom. San Francisco: Jossey-Bass.

Peeters, M. G., Van Tuijl, H. M., Rutte, C. G., \& Reymen, I. J. (2006). Personality and team performance: A metaanalysis. European Journal of Personality, 20(5), 377-396.

Phadnis, Shardul, \& Caplice, Chris. (2013). Global Virtual Teams: How Are They Performing? Supply Chain Management Review 17(4), 8-9.

Pinar, T., Zehir, C., Kitapçi, H. ,\& Tanriverdi, H. (2014). The Relationships between Leadership Behaviors Team Learning and Performance among the Virtual Team. International Business Research 7(.5), 68-79.

Pittinger, D. J. (2005). Cautionary comments regarding the Myers- Briggs Type Indicator. Consulting Psychology Journal: Practice and Research, 57(3). 210-221.

Potter, R. E., \& Balthazard, P. A. (2002). Understanding human interaction and performance in the virtual team. Journal of Information Technology Theory and Application, 4, 1-23.

Rutti, R., Ramsey, I. R., \& Li, C. (2012). The role of other orientation in team selection and anticipated performance. Team Performance Management, 18(1/2),41-58.

Sniezek, J. A., \& Henry, R. A. (1989). Accuracy and confidence in group judgment. Organizational Behavior and Human Decision Processes. 43(1), 1-28.

Spears, R., Lea, M., \& Lee, S. (1990). Deindividuation and group polarization in computer mediated communication. British Journal of Social Psychology. 29(2), 121-34.

Straus, M. A., \& McGrath J. E. (1994). Does the medium matter? The interaction of task type and technology on group performance and member reactions. Journal of Applied Psychology. 79(1), 87-97.

Straus, S. G. (1996). Getting a clue: The effects of communication media and information distribution on participation and performance in computer-mediated and face-to-face groups. Small Group Research, 27, $115-142$.

Steiner, I. D. (1972).Group Process and Productivity. New York: Academic.

Sternberg, R. J. (1997). The Concept of Intelligence and its Role in Lifelong Learning and Success. American 
Psychologist, 52(10), 1030-1037.

Taggar, S. (2000). Personality, cognitive ability, and behavior: The antecedents of effective autonomous work teams. Dissertation Abstracts International, 60(9-A).

Tindale, R. S., \& Larson, J. R., Jr. (1992a). Assembly bonus effect or typical group performance: A comment on Michaelsen, Watson, \& Black (1989). Journal of Applied Psychology. 77, 102-5.

Tindale, R. S., \& Larson, J. R., Jr. (1992b). It's not how you frame the question, it's how you interpret the results. Journal of Applied Psychology. 77, 109-10.

Tindale, R. S., \& Sheffey, S. (2002). Shared information, cognitive load, and group memory. Group Process. Intergroup Relations. 5(1), 5-18.

Tolcott, M.A., Marvin, F. F., \& Lehner, P. E. (1989). Expert Decision Making in Evolving Situations. IEEE Transactions on Systems, Man, and Cybernetics, 19(3), 606-615. doi:10.1109/21.31066.

Topi, H., Valacich, J. S., \& Rao, M. T. (2002). The effects of personality and media differences on the performance of dyads addressing a cognitive conflict task. Small Group Research, 33, 667-701.

van Knippenberg, D., \& Schippers, M. C. (2007). Work Group Diversity. Annual Review of Psychology, 58, 515-54 doi:10.1146/annurev.psych.58.110405.085546.

van Viennen, A., \& De Dreu, C. (2001). Personality in teams: Its relationship to social cohesion, task cohesion, and team performance. European Journal of Work and Organizational Psychology, 10, 97-120.

Varvel, T., Adams, S. G., Pridie, S. J., \& Ulloa, B. C. R. (2004).Team effectiveness and individual Myers-Briggs personality dimensions. Journal of Management in Engineering, 20(4), 141-146.10.1061/(ASCE)074297X(2004)20:4(141).

Yeatts, D. E., \& Hyten, C. (1998). High-performing self-managed work teams: A comparison of theory to practice. Thousand Oaks, CA: Sage.

Williams, E. A., \& Castro, S. L. (2010). The effects of teamwork on individual learning and perceptions of team performance: A comparison of face-to-face and online project settings. Team Performance Management, 16(3/4), 124-147.

Workman, M. D., Kahnweiler, W., \& Bommer, W. (2003). The Effects of Cognitive Style and Media on Commitment to Telework and Virtual Teams. Journal of Vocational Behavior, 63, 199-219. 


\section{APPENDIX A}

\section{Team Memo Assignment}

Taken directly from the proprietary online MBA course used in the study.

Team Memo for 30 points

Use your Team Discussion Board to introduce each team member and to exchange information about particular strengths, fields of study, and work experience. Your Team Discussion Board can be accessed from the Team Area Unit (below Unit 6).

Your team should then collaboratively pull this information together into a memo addressed to the instructor and the class (approximately 500-600 words), introducing your team and reviewing your team strengths and challenges. Include an assessment of your team style using Insights information. Post the memo to the main threaded discussion titled Team Memo Discussion.

Use this area to post the completed memo with all of your team information. Make sure to include team introductions, team strengths and challenges, and an assessment of your team style by using the Insights information.

To the left is an image of an Insights Wheel. You may find the Insights Wheel helpful for creating effective teams throughout your graduate program. Click here for a downloadable copy of the Insights Wheel.

Team assignment information is available on the Main Threaded Discussion in Unit 2 labeled Team Discussion, and your team has a private Team Threaded Discussion area under Team Area. You will use this team throughout the course and this private area for other collaborations.

Make sure to post the completed memo to the Unit 2 Team Discussion Thread by Sunday evening.

Team Tools:

- Your team also has a team-specific area in Doc Sharing, an email group list, and a private synchronous chat area, if you choose to use them.

- $\quad$ Teams sometimes use an instant-messaging service, such as AIM or chat.

- $\quad$ Part of your simulation grade is based on team participation. Setting up a specific time each week to check in may be helpful.

The final grade was determined by how well the Team Memo met the grading criteria and individual participation in the team assignment based on Team DB posts. 


\section{APPENDIX B}

\section{Unit 5}

Taken directly from the proprietary online MBA course used in the study. The Marketplace Simulation used in the course is from Marketplace Live, http://www.marketplace-simulation.com/. The following Marketplace Simulation Student Instructions and Executive briefings are taken from the course and provided by Marketplace Live.

The U5 Team Project is the completion of a Market Simulation that runs throughout the term. The Simulation has 4 quarters. The team's final performance at the end of U5 in the fourth quarter determines the team score for this assignment. Each individual's U5 Team Project score is based on peer evaluations and the team's success in the business simulation. At the end of simulation there is a "Cumulative Balanced Scorecard" for each team based on their simulation performance (Total Demand, Stock Outs, Emergency Loan, Bankruptcy, Net Income, Ending Cash Flow, Retained Earnings, Balanced Scorecard). Points for the team project are awarded by ranked finish. The team with the highest Cumulative Balanced Scorecard is awarded 75 points, second 68, third, 64, and fourth 60.75 points are also awarded for involvement based on peer reviews and time logged into the simulation. A perfect score would be 150 points.

What follows are the student directions. The Executive Briefings are the directions that the faculty member provides for each learner group at the start of the quarter.

\section{Marketplace Simulation Student Instructions}

Student sign up:

What you need: The Game ID and your "team" number from your professor. You are a team of one for this simulation. You will have an Advisory Board to work with. You will receive your student license number prior to beginning your Unit 2 assignments. The license number will be emailed to your student.kaplan.edu email address.

Executive Briefings with Students

In ground-based simulations, faculty meets with each student for a reflective briefing. It is important to incorporate this personal touch into our simulation experience. This personal touch is very rewarding. It is nice to see the students develop. You start to take a personal interest in each student, and the students love it.

Executive Briefing for Q1

This is a very interesting quarter for the students. They have almost 2,000,000 in their pockets and a sense that anything is possible. And, they are right. However, they have to start making choices that will affect them for the rest of the exercise.

The most important decision the students have to make in Quarter 1 is their initial strategic direction. They will have several opportunities to change this direction, but there is a tendency to stay with their first strategy throughout the game.

There are many strategies that the students can formulate. Fortunately, most of them can be successful if pursued smartly and aggressively. Thus, the big worry is not which of the many directions to take, but the rationale for taking any direction. Have the students thought through their options and considered the major implications and tradeoffs of each choice? Do they have a vision for how their firm will successfully compete in the marketplace? Most of the major strategic choices are highlighted in the strategic direction area within the software.

During your Quarter 1 executive briefing, probe to make sure the students have considered the following factors in their decision: 
1. Size of market for each market segment. Workhorse segment is the largest in terms of numbers. The Mercedes segment looks like a good size segment but this is deceiving because it is very difficult to satisfy their needs until the firm can offer several new $R \& D$ features in Quarter 5. The Traveler segment is moderate in size.

2. Profit potential of each market. Workhorse segment offers the greatest profit potential because it will typically result in large production runs, which drive down production cost, thus improving gross margins. The Mercedes would appear to have attractive profit margins, but the sales volumes are fairly small in the early quarters, thus production costs are very high. The Mercedes segment will not be profitable until new R\&D goes on the market in Q5 or later. The Traveler segment is also volume sensitive, but not as bad as Mercedes. This segment should be paired with a large volume segment in order to drive down production costs, thus improving gross margins.

3. Size of geographic markets. The largest markets will generate the largest amount of demand, all other things being equal.

4. Propensity of competitors to enter the market. The largest geographic markets and the Workhorse segment will attract the largest number of competitors. Since this is not hard for the students to forecast, some teams will avoid these markets. You might point out to these teams that competition is not always bad. Each additional competitor brings more attention to the product category and can actually improve overall demand. To be the only competitor in a geographic market or segment, can be bad news. There is a threshold of marketing that must be done to generate interest in the product. One competitor may not be able to stimulate the market sufficiently to make a good profit.

5. Cost to enter the market. The biggest geographic markets will cost the most to enter, but they have the biggest market demand. The small markets might be cheap, but they may not bring in enough demand to drive production costs down to the point that it is profitable. Small markets can be profitable if added to large markets. The large markets are needed to bring production costs down.

6. Cost to compete. The high-end of the market (Mercedes and Travelers) are expensive to serve. They require more expensive components and R\&D. The market will favor teams that can deliver superior performance. It will be unmerciful to those that try to get by with minimum technology.

Executive Briefing for Q2

This will be the toughest quarter for the students. They have to make a lot of difficult decisions with very little information. The anxiety level should be at its peak. You need to be encouraging, cautious and demanding. Encourage the students to try different ideas, to experiment with different advertisements, prices, manufacturing settings. They can learn a great deal from the market.

Encourage the students to be cautious. The students should use Quarter 2 to learn what the market wants and then use this knowledge in Quarter 3 to more aggressively pursue their objectives. They should walk before they try to run. They will be much smarter in Quarter 3 than they are in Quarter 2. They will learn what customers really like and do not like. They will learn how to run a factory, how to coordinate a broad set of marketing tactics and how to project cash flows. They will discover what their competition is trying to do and be able to take advantage of their weaknesses and defend against their strengths.

\section{Executive Briefing for Quarter 3}

The focus this quarter is on skillful adjustment. Each team needs to carefully study the available data, determine what needs fixing and what has gone well for the firm. Spend time on the problem areas. Make sure they understand the cause of the problem and the options for improving the situation. They can learn a great deal from the market data. They should not hesitate to copy a good idea.

This quarter might require some morale building. Firms with sizeable emergency loans (over 500,000) and large negative losses (over 800,000 minus) might be down in the spirits. They need to be pumped up, not artificially but through better decisions. Help them see how they can improve. If they know exactly what the problem was (i.e., low brand judgment, few sales people, etc.), their demand and fortunes should improve. 
Executive Briefing for Quarter 4

Activities and Guidelines on How to Review Tactical Plans and Pro Forma Statements for the Business Plan

Quarter 4 is the most difficult decision period for the teams. The teams must analyze the results of Quarter 3, make Quarter 4 decisions and prepare a detailed business plan. For this reason, the students should be given 2 weeks to complete Quarter 4 and prepare and present their business plan. They should have one week for Q4 and one week for the business plan.

Here is a suggested sequence of activities for Quarter 4 and the Business Plan.

1. The teams should analyze Quarter 3 results and complete Quarter 4 in the normal manner.

2. The teams should meet with you as the teams would normally regard Quarter 4 and their analysis and decisions.

3. Within a couple of days of completing Q4, the teams should complete the tactical plan and pro forma financial statements through Q6 and submit these to you for review. The tactical plan and pro formas can be reviewed within the team's software or on paper.

4. You should provide feedback on the quality of the planned tactics and pro forma projections. The revised tactical plan and the pro forma financial statements should be turned in with the business plan.

5. The teams should prepare the final Power Point presentation and submit it to you for review a couple of days before the final presentation.

6. You should provide feedback on the quality of the Power Point presentation.

7. The teams should practice the presentation and question and answer secession.

8. Each team is given 15 to 20 minutes to present and up to 20 minutes for Q and A.

9. Everyone on the team must participate in the presentation.

Executive Briefings for Q5

Q5 is a relatively quiet quarter for most teams. They have a plan and they are executing it. Most will feel good about the future and are feeling good about having worked through and presented a rather difficult business plan. Thus, there tends to be few serious problems at this time. They will show up in Q6.

Expect one in eight firms to go bankrupt in Q5. One in three will have emergency loans. Here are a few things to watch for that may cause emergency loans and bankruptcies in Q6.

First, teams that have not done any R\&D will face competitors with better brands. Unless they are competing on price with many distribution outlets, they will lose market share and will probably not make their forecasted numbers.

If a team has no $R \& D$ in progress, I strongly suggest that they begin an $R \& D$ program or find someone from whom they can license technology for Q6. Licensing is especially attractive for a team that is low on equity.

Second, there are aggressive teams out there developing their sales outlets. Very conservative teams will be surprised by the jump in demand for some of their competitors. Unless a firm is expanding sales outlets, it is falling behind the competition. You might push them on this point.

Third, the students will be introducing new brands into the market with new technology. There will be a tendency to drop the older brands in favor of the new ones. There is an opportunity here to use the older brands and compete on price and use the new brands to compete on value, at a higher price. If they only have high-priced brands, they will strangle their demand because their price image could be too high for the market. They need some balance. And, if they discontinue advertising for these older brands, they can save money and add to the margin or the ability to drop price. Effectively, they can take advantage of the loyalty built up over the prior quarters.

I like to advise teams to offer multiple brands to each segment. It is a good idea to have a good, better and best brand. 
Q6 Executive Briefing - Helping weak teams

Quarter 5 can be disastrous. One out of eight teams will have gone bankrupt in Quarter 5 and one in three may have emergency loans.

I would not worry too much about emergency loans. Most teams will recover from this minor setback. Bankruptcy is more serious.

Bankruptcy can occur among good teams because they have overspent on R\&D, new sales outlets and new factory capacity. However, these teams will most likely pull out of bankruptcy. Most of what they have done will create more demand which will drive down production costs and improve gross and net margins. As long as they do not become too timid in Quarter 6, they will do fine.

In the case of weak teams, they are typically surprised by the strong teams that have introduced brands with better $\mathrm{R} \& \mathrm{D}$ features, more advertising and more sales outlets. When strong competition is combined with a weak market, revenues will be down which will send profit margins deep into the red. 


\section{APPENDIX C}

\section{Unit 6}

Taken directly from the proprietary online MBA course used in the study.

Your final project involves preparing a Team PowerPoint presentation using your Simulation organization and focusing on where to go next with your organization at the end of Quarter 4 for 120 points. Points were allocated for the PPT, peer evaluations, plus engagement based on Team DB posts.

This PowerPoint presentation, with annotated notes, should be posted in the Final Team Project discussion area by Sunday evening.

For this assignment, use the following format to help organize your presentation:

Final Group Project Format

The key is to provide the future direction for your business based on the outcome of the Marketplace Simulation results from Quarter 4 and connect your strategy with the course concepts learned in GB500. As a group, lay the foundation in the beginning so your classmates understand your strategy for the simulation and then discuss where you believe your company should go from here. Within the slides, incorporate discussion in the Notes section that includes APA citations and connections to specific course materials.

To organize the PowerPoint presentation, use the format below:

1. Title Slide - include the name of your business and each group members' names (1 slide);

2. Introduction slide - discuss the company you developed and the strategy that you decided upon in the first quarter (1 slide);

3. Current situation - discuss the state of your business after the fourth quarter decisions were made. What was the position of your company in relation to each of the business functions decided each week? (1-2 slides);

4. Analysis of What Doesn't Work - explain what your team learned from the simulation related to the decisions that were made and what you would change if you could do it again (1-2 slides);

5. Direction to take - based on your strategy and current situation after quarter four decisions, discuss what direction you believe your company should take in the future and why. Be sure to include all of the business functions decided each week in the simulation. (6-10 slides);

a. Include details about what you will do with sales, marketing (price, promotion, distribution, product), expansion/growth, R\&D, human resources (sales force, compensation, etc.), production, etc. and how your suggestions will affect your bottom line.

b. $\quad$ Support your strategy with numbers when possible.

c. Further explain your bullet points in the notes section below the slide using APA citations to course materials.

6. Conclusion - wrap up your presentation with how you believe these changes and/or strategy will help make your business as successful as it can be (1 slide);

7. References-Include the full references cited within the presentation (1 slide).

Your PowerPoint presentation will likely be between 12-15 slides, give or take a few. Do not write in paragraph form on the slides. Remember that PPT presentations are bullet points, so be clear and concise as others do not get the benefit of your additional comments. In the Notes Section of the slides, be sure to expand your thoughts using APA citations to reference the course materials. This is the area to explain further the bullet points 